Bangladesh Journal of Bioethics 2010; 1(3):2-14

\title{
A PILOT STUDY FOR EVALUATING EGYPTIAN HEALTH WEBSITES: TECHNICAL AND ETHICAL PERSPECTIVES
}

\author{
Nahed M. Ali ${ }^{1}$, Amira Gamal' ${ }^{2}$ and Amr A. Mohamed \\ 1. Professor of Forensic Medicine and Toxicology, Faculty of Medicine, Suez Canal University, Egypt. \\ (Corresponding Author) Email: nmoustafa2004@yahoo.com \\ 2. Assistant Prof of Community, Environmental and Occupational Medicine, Faculty of Medicine, Suez \\ Canal University, Egypt. Email: gamalamira@gmail.com \\ 3. IT Department Director, Egyptian Diabetes Center, Egypt. Email:aibrahim@onlinediabetes.net
}

Keywords: E-health ethics- Health website.

\begin{abstract}
:
Background: The growing popularity of the Internet has made it easier and faster to find health information. Much of this information is valuable; however, the Internet also allows rapid and widespread distribution of false and misleading information. Aim of the work: To evaluate some of the Egyptian health websites from the Technical and Ethical perspectives and to compare the reliability of the different types of Egyptian health websites. Materials and Methods: This is a descriptive study. Search engines (eg. Google.com and Yahoo.com) were thoroughly searched for Egyptian health websites. Some of these websites were not accessible. Out of thirty two health websites, thirteen internet health websites were randomly selected and evaluated twice in this study. They were classified into 4 categories, official, professional, educational and private. The tool used in this study was a questionnaire developed by the research team depending on EHealth code of ethics, 2000 and international technical guidelines. The questionnaire consists of two main categories (technical and ethical). The technical evaluation includes (authority, objectivity, coverage, currency, design, privacy and security). The ethical evaluation includes (quality of information, informed consent and professionalism). A score for the questionnaire was developed by the research team to assess the websites. All statistical analyses were performed using the Statistical Package for Social Science (SPSS) version 11.0. Comparisons between ethical and technical categories were done using the student's t-test and ANOVA test for continuous variables and Pearson's Chi square test for categorical variables. Results: On evaluating the quality of information of the health websites, it is noticed that in $92.3 \%$ of the sample, medical care is provided by professionals and their information based on scientific studies. Around forty six percent $(46.2 \%)$ of the health websites do not mention the date of publication, date of recent update and the source of the information. Concerning the professionalism, $100 \%$ of the sample obeys laws and regulation in identifying themselves and mentioning the limitation of online consultation. $76.95 \%$ of the sample states clearly the purpose of the health website. Only $38.5 \%$ of them were recently updated. Privacy policy evaluation shows that $33.3 \%$
\end{abstract}


mentions if the system prevents unauthorized access to personal data while only $16.7 \%$ states how the user's personal data is stored and for how long. There is a statistically a significant change $(\mathrm{p}<0.05)$ on comparing the quality of information between the different types of websites. Both of the official and professional websites are better than educational and private websites. Conclusion: Some of the Egyptian health websites are reliable and up-to-date; some are not. Most of them are technically satisfactory. Evaluation of the health websites faces difficulties due to continuous updating. Recommendations: we should teach the health seekers to trust what they see or read on the Internet only if they can validate the source of the information and the authors and contributors should always be identified. It is necessary to establish mechanisms of Accreditation of Egyptian Health Websites. E-Health Ethics Training is very essential for the health professionals.

Introduction: Ethics can be viewed as a prerequisite for the success of medical practice. If the prerequisite is not in place to ensure trust of product or services provided, consumers will not utilize the product or services. In case of medical field, the public trusts the medical profession to regulate its own practices ${ }^{1}$. Knowledge and capabilities of new technology or an area of study often develop faster than the guidelines and principles needed for practitioners to practice ethically in the new arena. One area of rapid technological and economic expansion was that of the internet, in particular how quickly the internet is impacting and changing the practice of medicine in the $21^{\text {st }}$ century ${ }^{2}$. Internet health seekers may be healthy citizens with an enquiring mind, newly diagnosed or chronically ill patients and carer for a diagnosed person. Different factors affect the patient's safety on the internet as the quality of information, privacy of information, professionalism in online health care and informed consent. The internet has become and will continue to be a significant means by which individuals self educate with respect to health, and this self education has the potential to result in important changes in the dynamics of the physician-patient relationship ${ }^{3}$.

Concern has been expressed about the quality of medical information displayed generally on the internet. Some sites provide inaccurate or misleading information ${ }^{4 \& 5}$. The quality of information in health website plays a pivotal role in patient's safety. It is extremely variable from evidence based health care to practice of fraud and dangerous claims. Sometimes the medical care or advice is provided by a non professional person who does not state if this info based on scientific studied, expert consensus or personal experience or opinion. Many health websites do not mention the source the site or content provider has used with references or links to sources. US Food and Drug Administration (2005)_advised the health seekers to pay close attention to where the information on the site comes from. Many health and medical Web sites post information collected from other Web sites or sources. If the person or organization in charge of the site did not write the material, the original source should be clearly identified ${ }^{6}$. We should to be careful of sites that don't say where the information comes from. In case of drug or products, some health websites do not inform health seekers if they are approved by authorities or not. Fox, (2007) mentioned that Eighty percent of American internet users have searched for health information online. 
They are called "health seekers". Three quarters of health seekers said that they did not consistently check the source and date of the health information online. This translates to about 85 million Americans gathering health advice online without usually examining the quality indicators of the information they find. One possible reason for this diminishing diligence in checking sources and dates might lie with health websites themselves ${ }^{7}$. These concerns have led to the development of the ethical codes for the providers of medical information on the internet (Health Internet Ethics). Although these vary depending on the specific purpose and context of the proposed codes, there are common themes between many of them. There are also several, international ethical standards and guidelines for internet health sites. E-health code of ethics is the one of the commonest guidelines which ensures that all people worldwide can confidentially, and without risk, realize the full benefits of the internet to improve their health ${ }^{8}$. The large volume of health information resources available on the internet has great potential to improve online health services, but the critical question is how to differentiate between the appropriate and inappropriate information on both medical specialists and patients, many of health field members are trying to find an accredited criteria to evaluate the wide range of medical information available on the world wide web (WWW). Now we have a question, are the Egyptian websites providing health services reliable regarding ethical and technical criteria or not? To our knowledge, there may be no attempt made to evaluate the Egyptian health websites from the technical and ethical perspectives. So the aim of this paper was to evaluate the ethical and technical aspects of some Egyptian websites providing health services in the form of medical consultation, health related information and selling or advertising health products.

Materials and Methods: The study design of this work was a descriptive study. Search engines (eg. Google.com and Yahoo.com) were thoroughly searched by entering the key words healt websites, and Egyptian. Thirty two health websites were found, some of them were not accessible. Thirteen internet health websites were evaluated in this study. They were classified into 4 categories, official, professional, educational and private. Table (1) shows the evaluated Egyptian health websites.

There are 2 educational health websites, 3 official health websites which includes two for Ministry of Health \& Population and one for the Egyptian Medical Syndicate, 4 professional health websites which are developed by scientific societies, and 4 private health websites which are developed by doctors or health centres. Health websites were evaluated twice (February and June, 2007 respectively). The aim of the first evaluation was to test the validity of the tool while the aim of the second evaluation was to detect the changes in the previous evaluation due to update of the health websites. Masrawy website was omitted during the second evaluation due to removal of the health sector from it by the authors. 
Table (1): The evaluated Egyptian health websites

\begin{tabular}{|c|c|c|}
\hline Type & Name & Link \\
\hline 1. Official & Ministry of Health\& Population of Egypt & www.mohp.gov.eg \\
\hline 2. Official & Ministry of Health\& Population of Egypt & www.drguide.mohp.gov.eg \\
\hline 3. Official & Egyptian Medical Syndicate & www.ems.org.eg \\
\hline 4. Professional & Heart Journal, Cardiology Dep, Cairo U & www.hearj.com, \\
\hline 5. Professional & Egyptian Hypertension Society & www.ehs-egypt.net \\
\hline 6. Professional & Egypt's Medical Portal & $\underline{\text { www.egydoc.com }}$ \\
\hline 7. Professional & Egyptian Society of Paediatric allergy & www.espai-eg.org \\
\hline 8. Educational & Faculty of Med. Ain Shams U & www.com-med.ikalogic.com \\
\hline 9. Educational & Medical Education Online & $\underline{\text { www.medicaleducationonline.org }}$ \\
\hline 10. Private & The ultimate health portal for Egypt & $\underline{w w w}$.abcseha.com \\
\hline 11. Private & Consultant of Plastic Surgery & www.gamalekonline.com \\
\hline 12. Private & E-Males & $\underline{\text { www.erajol.com }}$ \\
\hline 13. Private & Online Diabetes.net & $\underline{\text { www.onlinediabetes.net }}$ \\
\hline
\end{tabular}

The tool used in this study was a checklist that consisted of two main categories: technical and ethical. The technical category evaluated 6 items including authority, objectivity, coverage, currency, design, privacy and security. The ethical category evaluated the quality of information, informed consent and professionalism, The tool was developed by the research team depending on: e-Health Code of Ethics, $2000^{8}$ for the ethical part and the several International Guidelines which are used in evaluating health websites as Health On the Net Foundation ( HON code of conduct for medical and health web sites ${ }^{9}$,Health Information Technology Institute, British Healthcare Internet Association, US National Institute of Health and others. All questions were answered as yes, no and not applicable, which equal to 0 and 1 for no and yes respectively and omitted from the score if not applicable. A score for the checklist was developed by the research team. For example, the quality of information item included 9 questions which means that the total score is 9 , if we have only 7 answered yes, then dividing 7/9 will give us the score and if we wish to express it as score percent we multiply it by 100 (7/9 x 100). The same process was repeated to calculate the total score for each of the ethical and technical categories. Then data was carried out and statistical analysis was performed using the Statistical Package for 
Social Science (SPSS) version 11.0. Data was presented as proportions and percentages, mean and standard deviations. ANOVA test for continuous variables was used. Figure (1) summarized the process of evaluation of the health websites.

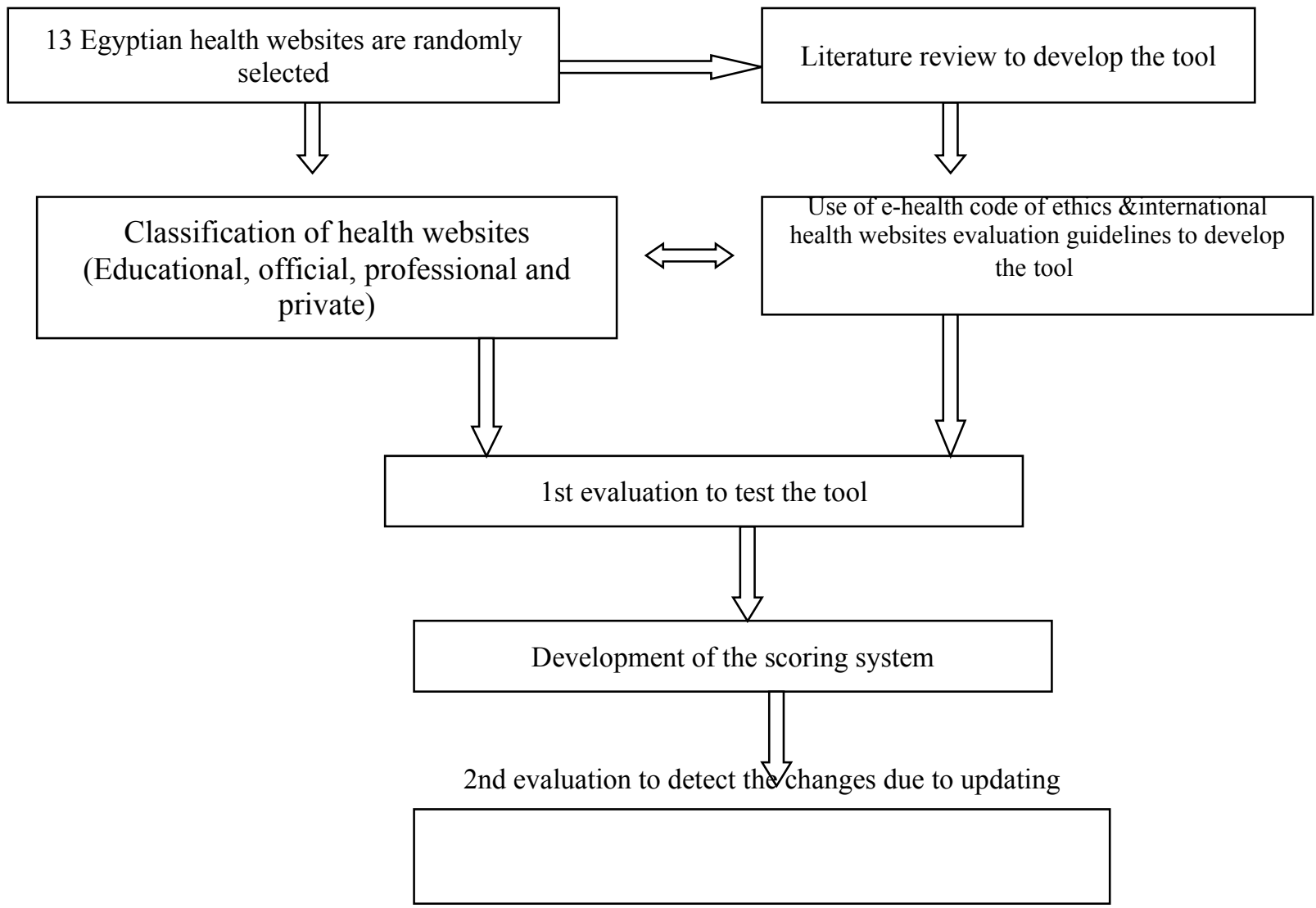

Figure (1): Summary of health websites evaluation process

Results: The ethical and technical criteria were applied to 13 Egyptian health websites. Table (2) shows results of the thirteen Egyptian Health Web- sites accessed by frequency with which the criteria are met. The evaluation of the quality of information shows that $92.3 \%$ of the sample provided medical care by professionals and the information is based on scientific studies, while $46.2 \%$ of the health websites do not mention the date of publication, date of recent update and the source of the information. $69.2 \%$ states that the 


\section{Table (2): Results of the thirteen Egyptian Health Web- sites accessed by frequency} with which the criteria were met

Parameter

Quality of information:

Medical care is provided by professionals

Information is based on scientific studies

Information is controversial

Language is clear

Mention the date for published information

Mention the date for review information recently

Mention the source website used with reference

There is an evaluation of contents of website

State if the products are approved by authorities

Informed consent

Type of data clear

Who collects data

How website use data

Professionalism

Fees for online consultation

Obey laws and regulation

Professional identify themselves

Limits of consultation online

Authority:

Authors clearly identified

Is there any institutional affiliation

Can easily contact authors for clarification

Objectivity

Is the purpose of the website clearly stated

Are the information presented relevant to the objective of the website

Coverage

Is the website bilingual

Is the website divided into sections which cover most of topics

Does the website satisfy the needs of its targeted visitors

Currency

Is the website updated recently

Is the revision date recent enough to account for the changes in the field

Are the links kept up to date

Design

Can the website be accessed reliably\& easily navigated

Is there any visual effects

Do visual effects enhance the resource, banners

Are there interactive features that increase usability

Can the website be accessed without additional viewer or plug in

Does the website provide the links for the software needed for opening the website pages

Privacy

Does the system prevent unauthorized access to personal data

Does the system tell how the user personal data is stored and for how long

\begin{tabular}{|c|c|}
\hline Proportion & $\%$ \\
\hline $12 / 13$ & 92.3 \\
\hline $12 / 13$ & 92.3 \\
\hline $9 / 13$ & 69.2 \\
\hline $13 / 13$ & 100 \\
\hline $7 / 13$ & 53.8 \\
\hline $7 / 13$ & 53.8 \\
\hline $7 / 13$ & 53.8 \\
\hline $11 / 13$ & 84.6 \\
\hline $8 / 13$ & 61.5 \\
\hline $4 / 5^{*}$ & 80.0 \\
\hline $2 / 5 * *$ & 40 \\
\hline $1 / 5 * * *$ & 20 \\
\hline $2 / 4^{\circ}$ & 50.0 \\
\hline $4 / 4^{\cdots}$ & 100.0 \\
\hline $4 / 4^{\cdots}$ & 100.0 \\
\hline $4 / 4 \cdots$ & 100.0 \\
\hline $13 / 13$ & 100.0 \\
\hline $8 / 13$ & 61.5 \\
\hline $12 / 13$ & 92.3 \\
\hline $10 / 13$ & 76.9 \\
\hline $13 / 13$ & 100.0 \\
\hline $6 / 8$ & 75.0 \\
\hline $13 / 13$ & 100.0 \\
\hline $12 / 13$ & 92.3 \\
\hline $5 / 13$ & 38.5 \\
\hline $5 / 13$ & 38.5 \\
\hline $10 / 13$ & 76.9 \\
\hline $13 / 13$ & 100.0 \\
\hline $10 / 13$ & 76.9 \\
\hline $7 / 10^{*}$ & 70.0 \\
\hline $9 / 13$ & 69.2 \\
\hline $5 / 13$ & 38.5 \\
\hline $1 / 8^{\text {sta }}$ & 12.5 \\
\hline $2 / 6^{*}$ & 33.3 \\
\hline $1 / 6^{\text {As }}$ & 16.7 \\
\hline
\end{tabular}

N.B: percent calculated from the total number of no and yes, $\mathrm{NP}=$ not applicable

* NP=8/13 (61.7\%), * NP=8/13 (61.5\%), ** NP=8/13 (61.5\%), $\mathrm{NP}=9 / 13(69.2 \%)$,

$\cdots N P=9 / 13(69.2 \%), \cdots \quad N P=9 / 13(69.2 \%), \cdots N P=9 / 13(69.2 \%),{ }^{\circ} N P=5 / 13(38.5 \%)$

* $\mathrm{NP}=3 / 13(23.1 \%)$, $\mathrm{NP}=5 / 13(38.5 \%),{ }^{*} \mathrm{NP}=7 / 13(53.8 \%),{ }^{\star \star} \mathrm{NP}=7 / 13(53.8 \%)$ 
presented information may be controversial and 61.5\% mentions that their products are approved by the authority. On evaluating the informed consent, $40 \%$ of the sample states who collects the data while only $20 \%$ mentioned how the websites uses data. Concerning the professionalism, $100 \%$ of the sample obeys laws and regulation in identifying themselves and mentioning the limitation of online consultation.

Regarding the technical evaluation: $100 \%$ of the sample identifies the authors, $76.9 \%$ of the sample states clearly the purpose of the health website, $75 \%$ of the sample is bilingual and only $38.5 \%$ of them are recently updated. The design evaluation shows that all the websites are accessed and navigated easily, but $69.2 \%$ of them have interactive features and only $12.5 \%$ provides the links for the software needed for opening the website pages. Privacy policy evaluation shows that $33.3 \%$ mentions that the system prevents unauthorized access to personal data while only $16.7 \%$ states how the user's personal data is stored and for how long.

Table (3) shows the frequency distribution of the 13 Egyptian internet health websites according to the score of the technical and ethical evaluation. It is shown that quality of information in 7 health websites is $100 \%$, while it is $37.5 \%$ in 3 health websites. Authority is $100 \%$ in 8 health websites and coverage is $76.9 \%$ in 10 health websites. Design item shows that only 2 health websites have a design score of $83.3 \%$ and privacy shows that 4 out of 6 health websites have no privacy policy. There is a significant change $(p<0.05)$ on comparing the quality of information between the different types of websites. Both of the official and professional websites are better than educational and private websites as shown in (Table 4).

Discussion: The internet can be a valuable source of health information, but not all sites are equally worthy or reliable. Information on the web may be incomplete, inaccurate, or overly simplified. The web lacks peer review or quality control; many sites are trying to sell a product, and are biased or out of date; and anyone can publish on the web whether they are an expert, or not $^{10}$.

In this study, the evaluation of the quality of information shows that $92.3 \%$ of the sample provided medical care by professionals and the information is based on scientific studies, while $46.2 \%$ of the health websites do not mention the date of publication, date of recent update and the source of the information, $69.2 \%$ states that the presented information may be controversial and $61.5 \%$ mentions that their products are approved by the authority. On evaluating the informed consent, $40 \%$ of the sample states who collects the data while only $20 \%$ mentioned how the websites uses data. Concerning the professionalism, $100 \%$ of the sample obeys laws and regulation in identifying themselves and mentioning the limitation of online consultation. 
Table (3): Frequency distribution of the thirteen health websites according to the score of technical and ethical evaluation

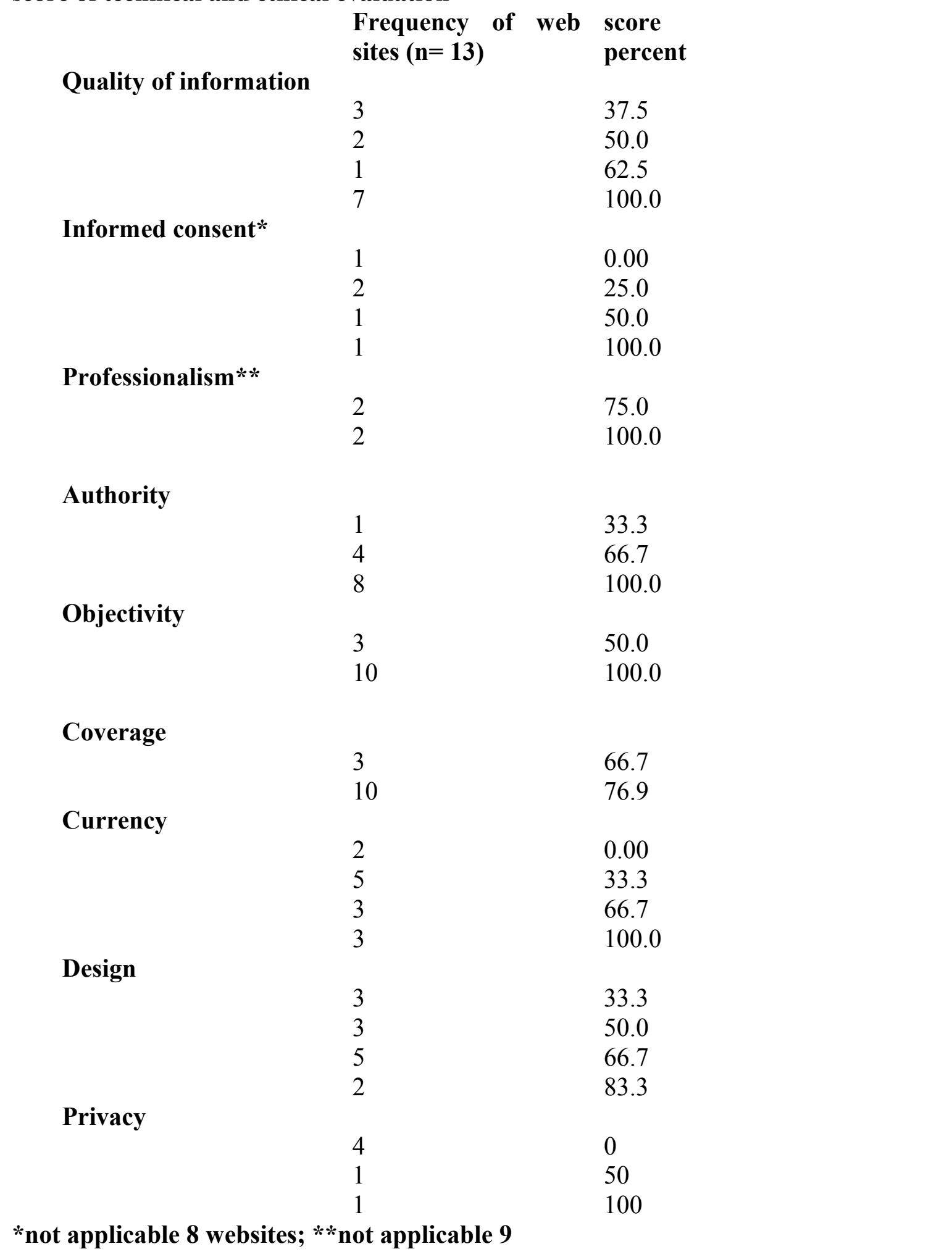


Table (4): Comparison of quality of information among the different types of health websites

\begin{tabular}{llc}
\hline & $\mathrm{N}$ & Mean \pm SD \\
\hline Official & 3 & $87.5 \pm 21.7$ \\
Professional & 4 & $100 \pm 0.0$ \\
Educational & 2 & $68.8 \pm 44.2$ \\
Private & 4 & $43.7 \pm 7.2$ \\
\hline
\end{tabular}

* ANOVA test was used in this table $\mathrm{F}=6.84 \quad$ P value $=0.011$

The National Cancer Institute (2005) and Medical Library Association (2008) mentioned that any Web site should make it easy for people to learn who is responsible for the site and its information. If the person or organization in charge of the Web site did not write the material, the original source should be clearly identified. Health-related Web sites should give information about the medical credentials of the people who prepare or review the material on the site. Any Web site that asks users for personal information should explain exactly what the site will and will not do with that information. It added that The Federal Trade Commission and the Food and Drug Administration are Government agencies that help protect consumers from false or misleading health claims on the Internet ${ }^{11 \& 12}$.

So it is important to mention that authors and contributors should always be identified and we have to avoid any online physician who proposes to diagnose or treat persons without a proper physical examination and consultation regarding our medical history.

According to Fox (2006) about 85 million Americans gathering health advice online without consistent examining the quality indicators of the information they found. Three quarters of them said they checked the source and date "only sometimes", hardly ever, or never. One possible reason for this diminished diligence in checking sources and dates might lie with health websites themselves. Just $4 \%$ of "frequently visited" health websites disclosed the source of information on their pages and $2 \%$ disclosed how the content is updated $^{13}$.

In the present study, it is noticed that the quality of information of both of official and professional websites is better than the educational and private websites $(p>0.05)$ which means that both of the official and professional health websites follow the criteria of international guidelines. This result shows that it is necessary to establish mechanisms of Accreditation of Egyptian Health Websites.

Aeree and Mee-Kyungs (2001) stated that anyone with a computer and internet access can publish on the web, so judging the trust worthiness of scientific and health related web sites becomes the responsibility of each individual user ${ }^{14}$. 
It is worthy to mention that in the academic community, the peer review process is used to ensure the validity and quality of the information presented in papers and reports. The general public, however, is more likely to understand a "seal of approval" from an individual or group commonly perceived as credible. Sites should indicate whether the information provided has been subjected to review, and if so, describe the process and the individuals involved.

In the present study, 4 out of 6 health websites have no privacy policy, $33.3 \%$ of the sample mention that the system prevent unauthorized access to personal data while only $16.7 \%$ states how the user's personal data is stored. Winker et al, (2000) stated that medical websites, more than any other type of site on the internet, should ensure visitors' personal privacy and prevent personal medical information, including patterns of use and interests, from being sold, purchased, or inadvertently entering the hands of marketers, employers, and insurers ${ }^{15}$. The National Consumers League (1999) stated that health care websites have access to an unprecedented amount of personal information about consumers. The public's concerns about internet privacy are significant, and heightened with regard to safeguarding their personal health information online ${ }^{\mathbf{1 6}}$. A survey of 1009 adults released in January 2000 by the California Health Care Foundation and the internet Health Care Coalition found that $75 \%$ of people were concerned about health websites sharing information without their permission and $17 \%$ of people did not even go online merely to seek health information due to their concerns over privacy. The good news is that nearly $80 \%$ of people said that the existence of a privacy policy that provides them with the ability to make choices about how and whether their information was shared had a positive impact on their willingness to engage in online health activities ${ }^{17}$. There was much work needed to provide consumers with an acceptable level of trust and confidence in the privacy safeguards and practices of health websites. Goldman et al, (2000) mentioned that at best, the privacy policies of health websites were confusing, inconsistent, weak, and often misleading when measured against the site's actual practices. A site with a privacy policy that disclaims liability for the actions of third parties on the site in effect negates the privacy policy ${ }^{\mathbf{1 8}}$.

The present study shows that $100 \%$ of the sample identifies the authors, $76.9 \%$ of the sample states clearly the purpose of the health website, $75 \%$ of the sample is bilingual and only $38.5 \%$ of them are recently updated. The design evaluation shows that all the websites are accessed and navigated easily, but $69.2 \%$ of them have interactive features and only $12.5 \%$ provides the links for the software needed for opening the website pages.

Eysenbach (2000) found that consumers assessing the credibility of a website primarily looked for the source, a professional design, language and ease of use, study participants never checked any "about us" sections of websites, disclaimer or disclosure statements. The average consumer paid far more attention for the superficial aspects of a site, such as visual cues, than to its content. The consumer assessed the credibility of sites based in part on the appeal of the visual design, including font size and color schemes ${ }^{19}$. Griffiths and Christensen (2000) evaluated the quality of web based information on treatment of 
depression to identify potential indicators of content quality and they found that although the sites examined contained useful information, their overall quality was poor ${ }^{20}$. Sites typically did not cite scientific evidence in support of their conclusions. Measures of quality such as display of authorship, attribution or references, currency of information and disclosure did not differ between popular and less popular sites ${ }^{\mathbf{2 1}}$. In similar findings, Kunst et al (2002) found that while there is a correlation between credibility features and accuracy of information, the associations is relatively $w_{e} \mathrm{k}^{22}$.

In this study, as the health websites are evaluated twice, some changes have been noticed due to continuous updating.

At last, physicians, nurses, pharmacists, therapists, and all other health care professionals who provide specific, personal medical care or advice online should abide by the ethical codes that govern their professions as practitioners in face-to-face relationships. They should also mention the limitations of online consultations.

Conclusion: Some of the Egyptian health websites are reliable and up-to-date; some are not. Most of them are technically satisfactory. Evaluation of the health websites faces difficulties due to continuous updating.

Recommendations: we should teach the health seekers to trust what they see or read on the Internet only if they can validate the source of the information and the authors and contributors should always be identified. It is necessary to establish mechanisms of Accreditation of Egyptian Health Websites. E-Health Ethics Training is very essential for the health professionals.

Study limitations: The present study is a pilot study to measure the adherence of the Egyptian health websites to the ethical criteria of e-heath code of ethics. It did not evaluate the quality of health related websites in a certain discipline or certain health topic, so our results cannot be generalized. Also since it is a pilot study, the sample size was rather fair and further studies with larger sample size are needed targeting certain disciplines and different types of health websites.

\section{References:}

1. Kassirer J P. Pseudoaccountability. Ann Intern Med. 2001 Apr 3;134(7):587-90.

2. Dyer KA. Ethical Challenges of Medicine and Health on the Internet: A Review. J Med Internet Res, 2001, 3(2):e23.

3. Broom, A. "Virtually $\mathrm{He}$ (1thy: The Impact of Internet Use on Disease Experience and the Doctor-Patient Relationship," Qualitative Health Research (2005), volume 15, number 3 (March), pp. 325-345.

4. Eysenbach, G. and Diepgen, T.L. 'Towards quality management of medical information on the internet: evaluation, labelling, and filter of information', British Medical Journal, (1998) Vol. 317, No. 71, pp.1496-1499 
5. Shepperd S, Charnock D, Gann B. Helping patients access high quality health information. Br Med J 1999; 319: 764-766

6. US Food and Drug Administration: How to Evaluate Health Information on the Internet. December 2005. http://www.fda.gov/default.htm

7. Fox, S. Online Health Research Is Widespread, but Few Check the Source and Date. Medscape General Medicine (2007); 9(1): 30.

8. Rippen H and Risk A: e-Health Code of Ethics. J Med Internet Res. 2000; 2(2):e9

9. Boyer C, Selby M, Scherrer JR, Appel RD.The Health On the Net Code of Conduct for medical and health Websites. Comput Biol Med. 1998 Sep;28(5):603-10

10. Health Affair Report: Untangling the Web: How to Find Quality Health Information. Published by the University of Washington Retirement Association http://www.washington.edu/admin/uwra

11. National Cancer Institute (2005): How To Evaluate Health Information on the Internet: Questions and Answers www.cancer.gov

12. Medical Library Association: A User's Guide to Finding and Evaluating Health Information on the Web, 2008. http://www.mlanet.org/resources/userguide.html

13. Fox, S. Online health search. Most internet users start at a search engine when looking for health information online. Very few check the source and date of the information they find. Washington DC: Pew Internet and American Life Project, 1615 L St., NW-Suite 700 Washington DC. 20036, 2006. 202-419-4500 http:// www.pewinternet.org/.

14. Aeree S, Mee-Kyungs. Evaluating health information sites on the internet in Korea: A cross-sectional survey. Asia Pacific J Public Health, 2001; 13 suppl:s19-22

15. Winker M A, Flanagin A, Chi-lum B, White J, Andrews K, Kennett R L, Deangelis C D, Musacchio R A. Guidelines for medical and health information sites on the internet: principles governing AMA web sites. American Medical Association. JAMA. 2000;283(12):1600-6. doi: 10.1001/jama.283.12.1600.

16. National Consumers League, "Consumers and the 21st Century," (1999): For additional information on consumer attitudes about Internet privacy see "Beyond Concern: Understanding Net Users' Attitudes about Online Privacy," at http://www.research.att.com/projects/privacystudy

17. Goldman J.;Hudson, Z.; Smith, RM. Privacy: Report on the privacy policies and practices of health Web sites. California HealthCare Foundation. 2000 Jan [2001 Apr 18].

18. Goodman KW, Miller RA. Ethics and health informatics: Users, standards and outcomes. In: Shortlife EH, Perreauit LE, editors. Medical Informatics: Computer application in health care and biomedicine. New York: Springer-vertag; 2000.p chap.7.

19. Eysenbach G. Consumer health informatics.BMJ. 2000, 24;320(7251):1713-6.

20. Griffiths KM, Christensen H. Quality of web based information on treatment of depression: cross sectional survey.BMJ.2000, 16;321(17275): 1511-5. 
21. Meric, Funda.;Bernstam, Elmer V.;Mirza, Nadeem Q.;Hunt, Kelly K.;Ames, Frederick C.;Ross, Merrick I.;Kuerer, Henry M.;Pollock, Raphael E.;Musen, Mark A.; Singletary, S Eva. Breast cancer on the world wide web: cross sectional survey of quality of information and popularity of websites. BMJ. 2002 Mar 9;324(7337):577-81. doi: 10.1136/bmj.324.7337.577.

22. Kunst, Heinke.;Groot, Diederik.;Latthe, Pallavi M.;Latthe, Manish.; Khan, Khalid S. Accuracy of information on apparently credible websites: survey of five common health topics. BMJ. 2002 Mar 9;324(7337):581-2. doi: 10.1136/bmj.324.7337.581.

\section{Competing interests}

The authors declare that they have no competing interests.

Authors' contributions

Nahed Ali helped conceived the idea of the study, contributed to the design of the study tool and evaluating the health websites. She wrote the manuscript

Amira Gamal contributed to the design of the study tool and evaluating the health websites. She did the data analysis.

Amr Mohamed conceived the idea of the study, contributed to the design of the study tool and evaluating the health websites from the technical point of view.

All authors read and approved the final manuscript

Corresponding Author:

Prof. Nahed Ali is the Head of the Department of Forensic Medicine and Clinical Toxicology, Faculty of Medicine, Suez Canal University, Egypt. She is a Certified Trainer of Research Ethics, Maryland University, USA, and an Ethics Expert among Global Ethics Observatory (GEObs), UNESCO

Nmoustafa2004@yahoo.com 